\title{
The Benign Interaction among Literary Creation, Criticism and Theory from the Perspective of Bottom Writing: Taking “Tu Ziqiang's Personal Sorrow" as an Example*
}

\begin{abstract}
XU Jiaona
Hanshan Normal University, Chaozhou, China

The heated conversations about Fang Fang’s “Tu Ziqiang’s Personal Sorrow” among the author, readers and critics are a typical example of the bottom literature which emerged in the 1990s. Starting with the controversies aroused by the novella, this paper discusses the relationships among literary creation, criticism and theory in the bottom writing. The problem of the social bottom is not only an economic or political problem, but also such a complicated cultural problem that has attracted increasing attention in the field of human science. As it were, around the problem of the bottom class, a new public field integrating different kinds of writing forms and various theoretical materials is formed. The Benign interaction among literary creation, criticism and theory will both benefit to the overall development of literature and provide resources for the theoretical construction.
\end{abstract}

Keywords: bottom writing, literary creation, literary criticism, literary theory, interaction

“Tu Ziqiang’s Personal Sorrow”, written by Fang Fang, has brought a lot of resonance and admiration just since published in the famous literary magazine October in February 2013. This award-winning novella has become a famous work of the new century focusing on the problem of bottom class and class mobility. However, at the same time there are also serious criticisms of the work. Therefore, great controversies have come into being and gradually developed in many aspects. The heated conversations about this novella among the author, readers and critics are a typical example of the bottom literature which emerged in the 1990s and write about the people and the lives at the bottom of the society. On the one hand, it reflects the positive intervention of literary criticism and theory in the process of writing, representing and narrating the bottom class. On the other hand, it shows that this is not only the economic or political problem, but also such a complicated cultural problem that has attracted increasing attention in the field of human science. As it were, around the problem of the bottom class, a new public field integrating different kinds of writing forms and various theoretical materials is formed. Starting with the controversies aroused by Fang Fang's novella, this paper will discuss the relationships among literary creation, criticism and theory, aiming at shedding some light on how to theorize the actual experience and turn it into resources for the theoretical construction.

\footnotetext{
* Acknowledgements: This paper was sponsored by China National Social Science Foundation "Research on the Fundamental Problems of the Contemporary Aesthetics and Criticism Patterns” (15ZDB023).

XU Jiaona is a Ph.D. of literary theory and an associate professor in School of Literature and Journalism of Hanshan Normal University. Her research interests are in modern literary theory and Marxist aesthetics.
} 


\section{The Creation and Reception of "Tu Ziqiang's Personal Sorrow"}

Fang Fang's recent works are characterized by being rich in content and theme, concerning current social events, and revealing the changes of the spirit of the times, which manifests a sharp sense of the reality and strong responsibility for the society. Fang Fang was inspired by a news story that a college student from a rural area went to college on foot and then depicted a complete story of Tu.

Tu Ziqiang was born in a poor remote rural village. After years of hard work, he finally got the admission to college. With the tuition collected from the whole village and the expectation from his folks, he started his trip to Wuhan by walk. During the trip, he did various kinds of odd jobs and also got a lot of help and respect from strangers. He lived a hard life in college, working at the school canteen, and doing tutoring as pastime jobs, and also received help from his classmates. Meanwhile, he studied hard and prepared for the postgraduate entrance exam, which was a more practicable and comparatively fair way for a poor student to achieve success. Unfortunately, he had to give up his plan for further study because of his father's sudden death. After graduation from college, he decided to stay in the city. However, he only got some temporary work and even encountered some misfortunes like the boss' back pay and going into hiding. He rented an apartment in the slums and lived an extremely frugal life. Worse still, as their old house in the village was damaged by a heavy snow storm, his mother came to live with him and caused a lot of trouble to him and eventually made him lose his job. The sad news that he had got the end-stage lung cancer became the last straw. He settled his mother in a temple and disappeared silently from the world on his way back to hometown.

The publishing of the novella in the magazine October in February 2013 instantly caused hot discussions. A month later, the offprint was issued. The magazine soon organized a seminar and published the transcript "Is this a Problem or a Doctrine?” That was an extraordinary move as to this famous literary journal. The novella has won the Award of Journal of Selected Novelettes and was nominated for Lao She Literary Award, and ranked at the top of the Best Chinese Novelettes in 2013.

The novella is popular because of its description of the most common social phenomena and the serious social contradiction and crisis. On the one hand, with the appearance of a series of problems including the disparity between rural and urban areas, the polarization between the poor and the rich and the uneven distribution of the education resources, it is more and more difficult for children from rural areas to change their lives through pursuing education. On the other hand, with the reality that many college students fell into big cities as an "ant tribe" and lived in distress and poverty, the dream that they are struggling for has been broken. The failure of individual struggle becomes the symptom of the time, and there appear catchwords such as "the difficulty of employment for college students”, “class solidification”, "loser”, "ant tribe”, “dwelling narrowness" and "dad-is-the-key” and so on. Therefore, Tu's personal sorrow has expanded as the common sorrow of the young generation, which has struck a responsive chord in the hearts of its readers.

However, shortly after the publishing of the novella, there are also objections in addition to the general acceptance of the novella. Different comments on the same work are not limited to the text, but extended to the understanding of the reality revealed in the text and the reception of the text by readers.

\section{The Intervention of Criticism}

Zeng Yuli's article “Only a Personal Sorrow” was published in The Literary Journal in August 2013, and a series of articles with strong criticism were also published in 2014, including Zhai Yejun's “Talk with Fang 
Fang about 'Tu Ziqiang's Personal Sorrow'”, Chang Yong's "the Obsolescence of Experience and the Provinciality of Propensity: Criticism of Fang Fang’s 'Tu Ziqiang’s Personal Sorrow'” and so on. Later, Wang Xueying wrote "On Fang Fang’s 'Tu Ziqiang’s Personal Sorrow”” while Niu Xuezhi responded with "Comment on the Criticism of Tu Ziqiang's Personal Sorrow"” and "Whether Criticism Needs Ultimate concern: Talking about the Comments on the Criticism of 'Tu Ziqiang's Personal Sorrow'” (See Zeng Yuli, 2013; Zhai Yejun, 2014; Chang Yong, 2014; Wang Xueying, 2014; Niu Xuezhi, 2014a; Niu Xuezhi, 2014b). Fang Fang also forwarded Zhai's article to her blog but claimed that she despised his text (Fang Fang, 2014). Despite the aggressive and improper words, and some malicious speculation that some critics wanted to be scathing to draw attention, the debate uncovers the intrinsic contradiction of the novella and some serious problems of the evaluation system, which deserves to be taken seriously. As the discussion develops, the criticisms in the last two years are more reasonable and precise while more valuable research directions are emerging.

The criticism of the novella focuses on the points as follow:

First of all, it exaggerates the urban-rural dual antagonism. The novella is first a story about "a countryman goes to town". When Tu got the admission to college, his fellow villagers saw him as "the favored person”, expecting him to gain a successful political position or a good fortune in the future and back to save his hometown out of poverty. Besides, he obtained admiration and goodwill from strangers on his way to college. The identity of "college student" was combined with "city"- the symbol of hope and success, and became an aura covering him. When studying in city, Tu himself was also deeply attracted by the glamorous bright side of the city, and when back home after his father's death he felt disgusted with the backwardness and lifelessness of villages, which spurred him to begin his individual struggle, try hard to change his fate and get rid of his family background. His goal was to settle down in the city. Paradoxically, in front of him was a deep gulf between the urban and the rural areas. In the end, Tu paid everything while gained nothing.

To push the urban and rural antagonism to the extreme, the author even fabricates some unreliable plots, such as Tu's exaggerated surprise when he saw a computer for the first time. The gap between rural and the urban children is also exaggerated, giving people a false impression that city people are all rich, come from good family background, and possess great interpersonal resources; rural people, however, have nothing at all. Tu's tragic fate also forms a sharp contrast to his classmates' success: the girl who also came from the countryside and worked together with Tu at the school canteen leaned on "a moneybag”; Ma, from a little bit better family than Tu, finally attracted a rich American girl with his good look and sense of humor, and successfully emigrated to the United States; Lee became a public employee and Zhao got a good job in the bank both by virtue of their family background. "The classmates all have prospects and dreams, while Tu is the only one who works hard with small gains” (Fang Fang, 2013a, p. 29).

The novella sets the city as the only framework for understanding Tu's sadness, and "while it intends to protest social injustice to young people, it is still firmly attached to the development logic which dominates the city process and the dreams of young people, without a moment's departure” (Luo Xiaoming, 2015, p. 162). And in the vision of the rural-urban, rich-poor polarization, the vast gray area in the middle is being erased, which hinders the revealing of the real survival situation of the "ant tribe", for after all the vulnerable groups at the bottom of the city are not only limited to the already poor students who come from rural areas.

Secondly, the character is flat and static. The viewpoint that Tu's sorrow is not personal but the "collective sorrow" of the generation is shared by the text, the writer, the publishers, as well as many readers and 
critics $^{1}$ (see Fang Fang, 2013a; Fang Fang, 2013b; Zhang Lijun, 2014), and this is one of the important values of the novella. However, the hero is not portrayed as a typical character in a typical environment. His experiences may be universal, and many people may have encountered more or less the same situation, have a similarly emotional experience, and will be prone to resonance. But the character is always single, flat and static. When it comes to the original purpose of writing, Fang Fang said:

I try to imagine how far a poor young man on his own alone, without playing any tricks, can go in the present society. Therefore, he should be one in our daily life. He was such an ordinary young man, without outstanding talent, handsome look, or special background, and at the same time he is not ambitious or aggressive (like many young people of this generation who don't care about the ideal, but just show their concern with the real life). What he has is his individual effort, his diligence, and his sincere goodwill towards others and life. He is self-aware, self-controlled, and self-respected without feeling inferior to anyone else. I try and let myself go through his life together with him and see what he can do and where he can go. (October Forum, 2013, p. 197)

Consequently, the novella has a very obvious feature of "character first". Throughout his short life, whether when he was living in the village, studying in the college or struggling in the work place, Tu was always with the same personal characteristics. Despite all the changes in his life, he was always a plain village young man who had poor family background, possessed flat capacity, and kept hard-working, extremely frugal, kind and dutiful, and most importantly he was happy and cheerful, facing all ridicule and misfortunes coolly without complaints or resistance. The novella gives readers an impression that Tu has never done anything wrong. As a result, when the writer needs him to end up in failure, she can only rely on fortuitous factors: he had to give up the postgraduate entrance exam because of his father's sudden death; the old house collapsed under the heavy snow, and then his mother had to live with him in the city and became a burden of his work and love life; finally he got a dramatic fatal illness. The times and the society, which the author thought to be responsible for Tu's fate, are only very abstract background in the novella without embodiments such as bad persons. Tu was well aware "that except for his fist boss who pocketed his wages and hided away, he had never been treated badly by others in the world; on the contrary, the warm care and help he received from many people were just like many hands appeasing him” (Fang Fang, 2013a, p. 33).

However, the characterization of Tu, although not as a typical image, but in the manner of a fable, represents the living status and the spiritual crisis of the "ant tribe" today: "identified with the social order, they bear the strain of contemporary life with no complaints and consciously give up their life ideals" (Wang Mochen, 2013). The novella triggers great resonance because there exists a strong feeling of sadness, despair, and hopelessness in the society, especially among the young generation. Though Tu's tragedy is filled with contingency, his sadness fits the atmosphere of the times. Therefore, the analysis of the mechanism of transforming the personal sorrow into the "collective sorrow" provides clues for us to grasp the social psychology and the collective feeling structures today.

The last is about the literariness of the novella. Since the beginning, some scholars have pointed out that the dramatic ending of the story weakens the novella's tragic power (See October Forum, 2013). However, the character is completely in accordance with the style of the novella. In depicting the sadness of Tu, whose main personal characteristic is optimistic and obedient to fate, the author uses refined words, moderates the emotions

\footnotetext{
${ }^{1}$ Fang Fang has said on many occasions that Tu's sorrow isn't personal. Originally published in October, the novella ends with "he never relaxes in his efforts, but has never received anything yet" (Fang Fang, 2013a) and thenthe writer adds to it a sentence "he thought, is really just your personal sorrow?" in its book form. On the cover of the book also printed the words "I am him and he is me; we are all Tu Ziqiang” and "it is the sorrow of one person, and even more of a generation” (Fang Fang, 2013b).
} 
and creates a mild, warm-colored background. As a result, there is a hint of sadness throughout the novella, which can even be said to reflect the traditional aesthetic taste of "being mournful but not distressing". It can help us to understand why Tu got the end-stage lung cancer rather than an early-stage one or other non-fatal diseases. Only in this way, would his character not be shaken since struggle is meaningless, and will there be no damages to the temperate aesthetic features of the novella. No matter how tragic the story is, such a narrative is ultimately sad and lyrical, rather than sharp and painful. Perhaps it is not the best way to tell the story since the pursuit of the literariness ultimately has to be achieved at the cost of damaging the rationality of the story and giving up a deep excavation of human nature, which results in the excessive suffering but the weak tragic effect of the novella.

The debating around "Tu Ziqiang's Personal Sorrow" has not been unique but a typical case in the bottom literature. Similar problems exist more or less in other writings. Therefore, there is an important and urgent need of work to sort, summarize, and inspect on the bottom literature as a whole on the theoretical level.

\section{Thoughts on the Theoretical Level}

Along with the abundance of the creation of bottom literature and the development of the criticism, some theoretical work has also been carried out concerning the definition, the intellectual resources, the artistic techniques, and the achievements and existing problems, but a lot of work needs to be done to establish a discourse system of bottom literature.

\section{The Relationship between Literature and Reality}

The literary reflection of real life, far from being a facsimile of the fragmentary experiences, means to grasp the essential things behind the hectic and confusing reality. Therefore, when writers, who feel threatened by the news media and approve of the argument that "the literary imagination has lagged far behind the reality", begin to race with the reality and pursue the novelty and the odd, we can only say they lose their confidence in literature because they give up grasping the essence of things. The bottom writing needs not only to face the reality, but to keep powerful questioning to drill down to the root, and this is to a large extent depends on the writers' knowledge horizon and views of the world.

Who should be responsible for Tu's sorrow? The author intends to tell us that it is the responsibility of the times and the society: "there are no other reasons, just because he is from the village, and is a son of peasants with little useful interpersonal resources and poor family background"; "the success of all individual struggle has to rely on the times in which we are living.” In fact these views impede a deep exploration of the tragedy in the novella. Although it shows the bankruptcy of the mythology of individual struggle, it conveys a belief in "individual struggle" itself and identification with "success", that is "to be rich or to be in authority" as Tu's classmate Ma said (Fang Fang, 2013a, p. 21). A critic argues that Tu is nothing different from his classmates and colleagues when it comes to their understanding of the society and themselves. They all see, perceive, and understand the society and themselves on the basis of "the relationship between human and things (wealth and power)"; the only difference lies in the fact that others make use of "the relationship between human and human" to establish "the relationship between human and things", while Tu is forced to work it out just with his individual struggle, which is neither a conscious nor an active choice, for he hasn't inherited any social capital, and is lack of the confidence and ability to accumulate social capital. A more in-depth problem is: "for 
all kinds of individual struggle with the goal of establishing the relationship between human and things, whether relying on the individual or expropriating the relationship between human and human, the starting and the end points are the increasingly hierarchical social structures” (Zhang Xiang, 2015, p. 55). Although we are sad when Tu failed, it may not be something joyful even if he is successful.

"We were so lucky growing up in the 1980s, an era when individual struggle was fully affirmed," said FangFang (Fang Fang, 2013b, back cover). What she ignored was the fact that there were only a very small portion of young men going to college and changing their fate in the 1980s, and more importantly, nowadays in our society, it is those young men in the 1980s that speculate as well as protect their vested interests, which helps to maintain the current unfair social pattern. Tu was living in an era of limited resources, increasing competition, and strict requirements for talents. Besides, the expansion of college enrollment and the devaluation of the diploma made the situation worse. Tu failed because he couldn't obtain superior resources through education and then change them into competitive social capital and resources, but there are still a few people in possession of more social capital which enables them to be successful. Sadly, a self-centered individual on either rising or falling paths does not care about the interests of other individuals or the collective; therefore, the fate of the bottom masses remains in the abyss of silence and darkness. Cai Xiang said: "People living at the bottom have the same dream. They think that they can change their living conditions through appropriation of cultural resources, which means going to school and pursuing education. This dream shows that the bottom class has accepted all the ideologies and moral patterns imposed by the ruling class. That is, they want to change not only their economic situation, but also their way of life and social status. They have a clear goal, which is to go into high-society circles, or at least the middle class. There is nothing wrong with it, but if it is ideological, the consequence will be serious: the bottom class will never have its own spokesperson again. This is one of the biggest hidden dangers in China. Once the intellectuals become members of the interest groups, they distance themselves from the bottom class” (Liu Xu, 2006, p. 213).

In the novella the cafeteria chef said: "In fact, I think there is no need for the government to run the university. For children of the poor, spending four years on campus is a waste of time, for they cannot get a good job when they graduate. For children of the rich, it is pointless as well, because they can get a good job without studying” (Fang Fang, 2013a, p. 32). This seems to well explain the fate of the characters in the novella. We do not want to further question whether Tu's classmates with social relations and family background are ignoramus or not. It is truly distressing that after four-years' studying at the university, Tu didn't attain a clear recognition of the society, and he was still lack of the ability of thinking, critique and resistance. Sadly, he was just a passive carrier of the ideology of modernization, wasting his youth and even his whole life following "the dreams of city" and "the mythology of success". How can education become an active field of cultural production rather than the tool of reproducing tool? How can people at the social bottom fight for survival and at the same time form their own "class consciousness" and values, rather than passively reproducing the cultural models of the middle-class and the existing social structures? These issues may probably deserve more discussion for the bottom writing.

\section{What Is Literature Doing?}

Since the new century, along with the development of the bottom literary creation and the diversification of the writers, it has always been the focus of the academic circles that how to express the bottom class and let them speak for themselves. The bottom literature reflects the strong desire of the silent majority to express 
themselves, which should be supported and encouraged. So it was a good sign that the "migrate workers' literature" won both private and official recognition and appreciation during the past decade, though they were generally in rough and poor quality. But now, nearly two decades later, it is obviously problematic if we keep staying on the "speaking" level instead of questioning "what to say" and "how to say". The bottom writing should especially take into account both the requirements of "what to say" and "how to say" to accomplish a work which will be integrated with both thought and artistic values.

Professional writers will consciously pursue the artistic quality in their works. For them, both the story and the characters are simply literary materials. They find a good story and tell it in a suitable artistic way, and thus a piece of literary work is completed. But once you choose the theme of the suffering people at the social bottom, it always means undertaking more social responsibility, questioning the humanity and facing the ethical dilemma. Facing the misery of people in the literature, both authors and readers will have difficulty in maintaining an indifferent attitude and a proper distance. A writer works mainly within the text, but readers may look at the outside of the text. In Chen Yingsong’s novella “a Dog Named Peace”, Peace the dog escaped from the poor countryside to the city with its owner, and eventually trudged back home after its owner was tortured to death in the city. From the artistic perspective, the ending is good because it is solemn and thought-provoking. Moreover, it echoes the beginning and makes the story well knitted. However, what will happen to the dog back home? Readers will be inevitably afflicted by this question.

Different from the predecessors who took the position of enlightenment and claimed "revealing the suffering and attracting the attention for healing” (as Lu Xun said) in their works in the May Fourth Movement, writers today wouldn't label themselves as spokespersons for the bottom class. So when they tried to find a way out for the suffering, their own despair and sense of powerlessness sometimes penetrated through the text. What the abrupt ending of “Tu Ziqiang's Personal Sorrow” reveals is simply Fang Fang's helplessness. Even Liang Hong, one of those who wrote about the bottom class in the documentary form, also couldn't help feeling sad at the end of her Exodus from Liang Village: "I just want to leave. I want to immerse myself in the midst of this sad melody, to escape the sadness and a clear indifference in my heart. Zhu and I are as close as flesh and blood, but I still treat him with such abnormal indifference. I will eventually go away from Liang Village” (Liang Hong, 2013, p. 305).

Writers may look down at, look straight ahead or look up to the object, but none of these perspectives itself is superior to others. What is important is whether they portray the real living conditions of the bottom class, raise new questions, and create a distance and space for reflections or improvement in the text.

\section{What Is Criticism Doing?}

The estrangement between writers and critics does not appear only today or only in China. But a good criticism will do no harm to the literary creation and is crucial for the latter to be widely accepted and produce an impact. It may be understandable when the writers of "personalized writing" immerse themselves in their own world without hearing voices from the outside, while it is not the same for the writers who choose the bottom class as the object. It is impossible to write a work which truly reflects the real life if only relying on the limited experiences and imagination alone, without a correct understanding of the underclass problems and a fully deep reflection on the reality.

The more important thing is that critics tend to talk to writers, but in fact they should talk to their readers, among them including some theorists. There is nothing inappropriate for a critic to be connected with the 
reality through the literary text and develop the issues that the text presents in a wider context for further discussion. On the contrary, this is the special value of literature, because it provides a unique way of looking at the world and reveals some true faces of the real life which you can't see anywhere else.

Since the publishing of "Tu Ziqiang's Personal Sorrow”, active reflections and heated discussions have emerged in a lot of critical essays on some actual issues such as the intergenerational transmission of poverty, the consolidation and mobility of social stratum, how societies become more fair, how to break the thinking pattern of urban-rural dualistic opposition etc. In fact, instead of limiting itself to the text, the bottom literary criticism has concerned a wide range of issues while invoking all kinds of theoretical resources, such as the thought and perspectives of economics, sociology, history, politics, and ethics etc., so as to eliminate cognitive mistakes and provide true knowledge about social reality, to avoid value lost and provide value guidance. Bottom literary criticism is bound to be mixed with other knowledge and culture outside the literary field, with the hope of the formation of thoughts and ideas which have greater explanatory power to the reality.

\section{The Theorization of the Literary Experience and Practice}

The bottom literature is supposed to be realistic, public, and earthly, and have a reflective and critical potential, so its rise may be helpful to cure the disease of the contemporary Chinese literature, which has the symptom of being detached from reality, captured by a strange cycle of talking to themselves, addicted to desire and sensory stimulation and coerced by consumerism. Currently, however, the development of bottom literary creation is uneven and has many problems. Therefore, it is a very important and urgent task to develop a reasonable and effective pattern of theory from the creation and criticism of bottom literature, which will justify the rationality and the value of bottom literature, analyze the development process, forecast and guide its future, provide paradigms and concepts for criticism and research, and construct an explanatory system with a clear position, right viewpoints and open orientations.

In turn, the bottom literary creation and criticism also provides powerful support for the development of theory. Theory does not necessarily emerge from reality, but if it is unable to face the reality and intervene in reality, it will be lifeless. The current construction of literary theory can employ many complex theories, but all should be on the basis of an explanatory power to the present practice and the cultural phenomenon, whether it is to emphasize the application of western theories in China, or the modernization of the ancient theories. The standpoint of the theory construction should be the reality of literary creation and acceptation. When theory only works to make specifications, it will be disconnected from literary practice and become increasingly marginalized.

\section{Conclusion}

Although many people believe that bottom literature contains a mixture of good and bad works, and its future remains in doubt, but the bottom class is not theoretical but real. As long as the bottom class exists, it will be represented in literature. To promote the development and prosperity of bottom literature, the intervention of criticism is a must, and the theory will also be useful. The bottom writing today in China has formed a public sphere where there exist active dialogues among various fields, such as creation, criticism, literary and cultural studies, and so on. The interaction not only benefits the development of literary disciplines, providing an opportunity to solve the problem that theory is seriously disjointed from creation and criticism, but also helps to represent, understand, and solve the problems of the bottom class. 


\section{References}

Chang Yong. (2014). The Obsolescence of Experience and the Provinciality of Propensity: Criticism of Fang Fang’s “Tu Ziqiang's Personal Sorrow”. Literary Journal, 24 April.

Chen Yingsong. (2006). “A Dog Named Peace.” A Dog named Peace. Beijing: Baihua Literature and Art Publishing House.

Fang Fang. (2013a).“Tu Ziqiang’s Personal Sorrow.” October, 2, 4-47.

Fang Fang. (2013b). Tu Ziqiang’s Personal Sorrow. Beijing: Beijing October Literature and Art Publishing House.

Fang Fang. (2014). Fang Fang: How do You Look at the Criticism on “Tu Ziqiang’s Personal Sorrow”. Beijing Literature, 6.

Liang Hong. (2013): Exodus from Liang Villiage. Guangzhou: Huacheng Publishing House.

Liu Xu. (2006). An Interview with Cai Xiang. Bottom Narration: the Crack in the Discourse of Modernity. Shanghai: Shanghai Chinese Classics Publishing House.

Luo Xiaoming. (2015). The "Personal Sorrow” in the Urban Structure. Literary Review, 2, 159-166.

Niu Xuezhi. (2014a). Comment on the Criticism of “Tu Ziqiang’s Personal Sorrow”. Literary Journal, 24 April.

Niu Xuezhi. (2014b). Whether Criticism Needs Ultimate Concern: Talking about the Comments on the Criticism of "Tu Ziqiang's Personal Sorrow”. Hundreds of Comments, 5, 34-40.

October Forum. (2013). “Is This a Problem or a Doctrine?”. October, 5, 190-197.

Wang Mochen. (2013). Fang Fang: the Power and the Blindness of the Thoughts. Beijing Daily, 1 August.

Wang Xueying. (2014). On Fang Fang’s “Tu Ziqiang’s Personal Sorrow”. Literary Journal, 24 April.

Zeng Yuli. (2013). Only a Personal Sorrow. Literary Journal, 22 August.

Zhai Yejun. (2014). Talk with Fang Fang about “Tu Ziqiang’s Personal Sorrow”. Literary Journal, 10 April.

Zhang Lijun. (2014). This is not a Personal Sorrow: a Review of Fang Fang’s “Tu Ziqiang’s Personal Sorrow”. Social Outlook, 1, 77-78.

Zhang Xiang. (2015). On the Crisis of the Ideology of Individualism in Modern Literary Narratives. Literary Review, 1, 53-62. 